\title{
Spectrum of Haematological Abnormalities in Patients of Multiple Myeloma
}

\author{
Kiran Aamir', Muhammad Hanif ${ }^{2}$, Hina Abbas $^{3}$, Aamir Ramzan $^{4}$
}

\begin{abstract}
Background: Multiple myeloma is plasma cell dyscrasia characterized by uncontrolled proliferation of plasma cells and a distinctive biological behavior. It is an uncommon hematological malignancy which primarily affects older individuals.

Objective: To determine clinico-hematological profile of Multiple Myeloma patients.

Material and Methods: It is a retrospective study conducted at a tertiary care hospital for a period of 6 month in which 55 patients diagnosed as Multiple myeloma were enrolled. Data of 55 cases of multiple myeloma was analyzed.

Results: Fifty five confirmed cases of MM were identified. There were 44 male and 11 female with a male to female ratio of 2:1. The frequency of multiple myeloma was high in patients with age 60-69 years. The median age of all patients was 56yrs (range 34-75). Anemia was present in $96.3 \%$ of patients $51 \%$ showed thrombocytopenia and $15 \%$ showed leucopenia. $91 \%$ of patients had ESR values above $80 \mathrm{~mm} / \mathrm{hr}$. Serum of $93 \%$ patients showed M.band in SPE. Bone marrow of $45.4 \%$ patients had $11-20 \%$ plasma cells, marrow of $20 \%$ of patients contain $21-60 \%$ cells while that of $34.5 \%$ patients contain $>60 \%$ plasma cells. It was observed that some of those patients with plasma cells $>60 \%$ showed severe anemia, severe thrombocytopenia and severe leucopenia. Radiographic examination showed lytic lesions in all patients

Conclusions: Our analysis shows that clinico-pathological features of multiple myeloma patients in Pakistan are comparable to published data.
\end{abstract}

Key words: Multiple myeloma, Anemia, Thrombocytopenia, hematological profile, plasma cell dyscrasia

This article may be cited as: Aamir K, Hanif M, Abbas H, RamzanA.

Spectrum of Haematological Abnormalities in Patients of Multiple Myeloma. J Saidu Med Coll Swat 2020;10(1):08-12

\section{INTRODUCTION}

Multiple myeloma is a disorder characterized by uncontrolled proliferation of plasma cells. All these proliferative plasma cell disorders are collectively called plasma cell dyscrasia ${ }^{1,2}$.Plasma cell is specialized white blood cell of lymphoid lineage of $B$ phenotype that is designed to produce antibodies $^{3}$. These abnormally proliferating plasma cells accumulate in bone marrow to an extent of suppressing and replacing normal hematopoiesis, also there is subsequent overproduction of monoclonal paraproteins that are produced by clones of malignant plasma cells.

Myeloma is a global disease with increased incidence in high income countries as compared to countries with low sociodemographic index. However increasing incidence is observed now in middle SDI countries and East Asia from 1990 to 2016.MM although constituting only $1.1 \%$ of all cancers but it accounts for $10 \%$ of all hematological malignancies ${ }^{4}$.Patients usually

\footnotetext{
1. Department of Pathology, Liaquat University of Health Sciences Jamshoro,

2. Department of Pathology, Bolan Medical College, Quetta

3. Department of pathology, Dow Medical College, Karachi

4. Sindh Institute of Urology and Transplantation, Karachi
}

Correspondence: Dr. Hina Abbas

Department of Pathology, Dow Medical College, Karachi

Email:hina.abbas@duhs.edu.pk
Diagnosed at age of $60-65$ years but very few almost $<2 \%$ are under 40 years ${ }^{5}$.

An interesting feature of multiple myeloma is that these malignant cells not only accumulate in the bone marrow but also produce abnormal antibodies which on one hand leads to the suppression of normal haematopoiesis by malignant plasma cells hence producing symptoms and clinical manifestations of cytopenias and on the other hand these abnormal antibody production also causes severe clinical manifestations ${ }^{6}$. In addition the expanding marrow also gives rise to osteolytic lesions and bone pain. Renal insufficiency is also a manifestation of multiple myeloma ${ }^{7}$.

Previous studies have shown that clinical features of multiple myeloma include bone complication $80 \%{ }^{8}$, pancytopenia $1 \%{ }^{9}$, anemia $85-100 \%{ }^{9}$, hypercalcemia $80 \%^{8}$, nephropathy $50 \%{ }^{10}$, bacterial infection $23 \%^{8}$, neurological abnormalities $5 \%^{8}$ coagulopathy and extramedullary disease $5 \%^{8}$.Normally plasma cells constitute only $5 \%$ of all nucleated cell count in bone marrow but in patient with multiple myeloma these abnormal plasma cells increase more than $10 \%$ at least $^{10}$. 
Hematological abnormalities occur with varying frequency in MM patients. This study is conducted to see the spectrum of patients presenting with multiple myeloma and to see the hematological complications that subsequently occur in these patients due to malignant infiltration. The common clinical features of MM which are the hall mark of disease are osteolytic lesions along with normocytic normochromic anemia, renal insufficiency and recurrent bacterial infections ${ }^{(11)}$. These complications occur in patients at varying frequency. In addition to anemia, bone complications and hypercalcemia being most frequent ${ }^{11}$. Cytopenic complications usually occur due to replacement of normal hematopoietic bone marrow by malignant plasma cells also there is elevation of erythrocyte sedimentation rate (ESR) which can be an incidental finding ${ }^{12}$. One more vital thing to reach definitive diagnosis of $M M$ is demonstration of monoclonal protein either in serum or in urine. In cases where monoclonal protein can't be detected like in non-secretory myeloma which accounts for less than $3 \%$ of all MM cases, the clonality is established by light chain restriction method either by immunohistochemistry (IHC) or by flow cytometry however lytic bone lesions are easily demonstrable on $x$ ray $^{13}$.

The purpose of this study is to determine frequency of hematological abnormalities i.e. anaemia, leucopenia and thrombocytopenia in multiple myeloma patients admitted in Sindh Institute of Urology and Transplantation (SIUT) and to compare the findings with international data so we can get an idea of variation in our population.

\section{MATERIALAND METHODS}

This study was conducted at Sindh institute of urology and transplantation
Study design: Descriptive cross sectional study Duration of study: 6 months

Place of study: Department of Hematology and Department of Nephrology at Sindh Institute of Urology and Transplantation, Karachi.

Sample technique: Non probability, purposive sampling.

Inclusion criteria: Patients meeting the diagnostic criteria of MM i.e.; presence of monoclonal plasma cells $>10 \%$ in bone marrow, monoclonal protein in serum or urine on SPEP or IFE, and presence of any 1 or more of the myeloma related organ dysfunction including hypercalcemia, anemia, lytic bone lesions and renal insufficiency

Exclusion criteria: none

\section{Data collection procedure:}

Retrospective Data of diagnosed cases of multiple myeloma was recorded including age, gender, presenting complaint. CBC, peripheral film, ESR,bone marrow examination, Serum calcium, Total protein, $A / G$ ratio, urea, creatinine, urine $D R$, serum and urine Immunofixation electrophoresis along with X-ray skull or long bones. This research study was approved by ethical review committee SIUT. Ethical issues were considered and maintained throughout the study.

\section{RESULTS}

In a retrospective study of 6 months duration in which 55 patients diagnosed as Multiple myeloma were enrolled. Data of 55 cases of multiple myeloma was analyzed.

Table 1: shows the age and sex distribution of all cases included in study. Table 2: shows the clinical and laboratory features in patients of multiple myeloma while table 3 shows frequency of anemia

Table 1. Age and sex distribution of patients $(n=55)$

\begin{tabular}{|cc|c|c|}
\hline factor & No of patients(n) & Percentage (\%) \\
\hline Age & & 5 & 9 \\
& 440 & 11 & 20 \\
& $40-49$ & 14 & 25.4 \\
$50-59$ & 18 & 32.7 \\
& $60-69$ & 7 & 12.7 \\
\hline Gender & $>70$ & 44 & 80 \\
& Male & 11 & 20 \\
\hline
\end{tabular}


Table 2. clinical and laboratory features in patients of multiple myeloma ESR: Erythrocyte sedimentation rate; M.band; Monoclonal band SPE: Serum protein Electropheresis, IFE: Immunofixation electropheresis

\begin{tabular}{|c|c|c|}
\hline Clinical features & No of patients(n) & $\begin{array}{c}\text { Frequency } \\
(\%)\end{array}$ \\
\hline Anaemia & 53 & 96.3 \\
\hline Thrombocytopenia & 28 & 51 \\
\hline Leucopenia & 8 & 15 \\
\hline ESR>80mm/hr & 50 & 91 \\
\hline M.band in SPE & 51 & 93 \\
\hline Plasma cells & 25 & 45.4 \\
$11-20 \%$ & 11 & 20 \\
$21-60 \%$ & 19 & 34.5 \\
$>60 \%$ & 55 & 100 \\
\hline Lytic lesions & 29 & 83 \\
\hline M.band in urine IFE & & \\
\hline
\end{tabular}

Table 3. Anaemia according to age $(n=53)$

\begin{tabular}{|c|c|c|}
\hline Age range(years) & No of patients(n) & Frequency $(\%)$ \\
\hline$<40$ & 7 & 13.2 \\
\hline $41-50$ & 10 & 18.8 \\
\hline $51-60$ & 20 & 37.7 \\
\hline$>60$ & 16 & 24.5 \\
\hline
\end{tabular}

\section{DISCUSSION}

In our study $32.7 \%$ of the patients are between the age group 60-69 years. This finding is quite comparable to the results that were stated previously i.e: $38 \%$ and $23 \%$.It can be seen that multiple myeloma is still a disease of elderly population the reason may be one of those associated with aging, moreover more older patients are more expected to seek medical care for bone pain ${ }^{9}$. Only 1 patient $(2 \%)$ was under 40 while there was not a single case aged less than 30 years among those. So it unveils that $\mathrm{MM}$ is still infrequent in age group of less than 30 .It is in concordance with other studies too as one retrospective study conducted in Myo hospital on a very large no of cases also showed only $2 \%$ cases under 40 years and again the percentage is constant since the actual data base for multiple myeloma was developed in $1960^{9}$.

In our study anemia was present in $96.3 \%$ patients although anemia is a major manifestation that is demonstrated in almost two third of MM patients in other studies also but percentage is higher in our study as compared to other study in which $73 \%$ of MM patients had anemia ${ }^{14}$. Anemia can be either due to decreased production of erythropoietin resulted from renal in sufficiency or can be due to replacement of normal erythroid cells by malignant plasma cells however in some patients anemia is not proportional to the degree of marrow suppression or renal insufficiency. It is thought to be related to cytokine mediated marrow suppression $^{15,16}$. There is also a possibility of decreased red cell survival but evident immune hemolytic anemia is rare ${ }^{17}$.

Reported frequency of anemia in previous studies was $75 \%$ while thrombocytopenia and leucopenia are less frequently observed i.e5\% and 20\% respectively. Another study showed anemia in $82 \%$ of the patients whereas leukopenia and thrombocytopenia were observed in $15 \%$ and $23 \%$ of patients ${ }^{18}$.In our study these Parameters were frequently observed i.e. $96 \%$ anemia $51 \%$ thrombocytopenia and $15 \%$ leucopenia .Various causes may be attributed to development of these cytopenias among which most obvious is progressive myelosuppression during the disease course by increasing no of malignant plasma cells however other reasons may also be recognized. Functional impairment may also be responsible 
for the depletion of hematopoietic stem cells (HPSCs) in which Transforming Growth Factor- $\beta$ (TGF- $\beta$ ) signaling pathway activation in HPSCs is an important mechanism which has strong antiproliferative effect on HPSCs. Another proposed mechanism is the clearance of erythroid transcription factor GATSA-1in combination with direct Cytopenic effect of Fas ligand (FAS-L) and TNF-related apoptosis-inducing ligand (TRAIL) expressing MM cells in on inactive erythroblasts ${ }^{19}$. This myelosuppressive effect of myeloma cells is very important and critical as drugs that are usually given as treatment of $\mathrm{MM}$ also have myelosuppressive effect that can worsen the condition and may aggravate need for transfusion during the course of treatment ${ }^{20}$.

In our study out of 55 patients of MM, 93\% had monoclonal $(\mathrm{M})$ protein in serum and $80 \%$ had $M$ protein in urine on Immunofixation electrophoresis (IFE).The results are very much similar to other study that showed $93 \%$ patients demonstrating $M$ protein in serum while $78 \%$ patients had M protein in urine ${ }^{9}$. Although the previous study was conducted on very large no of cases and sample size in our study is quite small. In patients who do not secrete any Immunoglobulins (Igs) in serum or urine the condition is termed as nonsecretory myeloma (NSM). In such cases determination of clonality of plasma cells may be problematic. NSM accounts for around $3-5 \%$ cases of total MM population but we couldn't identify any as our study included very few cases of $\mathrm{MM}^{21}$.

\section{CONCLUSION}

It can be concluded that anaemia is more frequently present than thrombocytopenia and leucopenia in multiple myeloma patients high percentage of plasma cells in bone marrow has strong relation with cytopenias clinicopathological features of MM are considerably parallel with the international reported data MM patients are generally treated with alkylating agents and that can worsen the situation so we need to do special care while managing such patients and all these hematological parameters should be evaluated carefully

\section{REFERENCES}

1. Alexandrakis MG, Goulidaki N, Pappa CA, Boula A, Psarakis F, Neonakis I, Tsirakis G. Interleukin-10 induces both plasma cell proliferation and angiogenesis in multiple myeloma. Pathology \& Oncology Research. 2015 Sep 1;21(4):929-34.
2. Licandro R, Hofmanninger J, Weber MA, Menze B, Langs $G$. Predicting Future Bone Infiltration Patterns in Multiple Myeloma. InInternational Workshop on Patchbased Techniques in Medical Imaging 2018 Sep 20 (pp. 76-84).

3. Nutt SL, Hodgkin PD, Tarlinton DM, Corcoran LM. The generation of antibody-secreting plasma cells. Nature Reviews Immunology. 2015 Mar;15(3):160-64.

4. Sagale MS, Dangali DP, Rane SR Clinicohematological profile of multiple myeloma in tertiary care Hospital, Pune. Indian Journal of Basic and Applied Medical ResearchDiagnostic research special issue. 2017 Mar;6(2):25-30.

5. Rajkumar SV, Kumar S. Multiple myeloma: diagnosis and treatment. InMayo Clinic Proceedings 2016 Jan 1 (Vol. 91, No. 1, pp. 101-119).

6. Willrich MA, Katzmann JA. Laboratory testing requirements for diagnosis and follow-up of multiple myeloma and related plasma cell dyscrasias. Clinical Chemistry and Laboratory Medicine (CCLM). 2016 Jun 1;54(6):907-19.

7. Sethi S, Fervenza FC, Rajkumar SV. Spectrum of manifestations of monoclonal gammopathyassociated renal lesions. Current opinion in nephrology and hypertension. 2016 Mar 1;25(2):127-37.

8. Smith A, Roman E, Howell D, Jones R, Patmore R, Jack A, Haematological Malignancy Research Network (members listed in). The Haematological Malignancy Research Network (HMRN): a new information strategy for population based epidemiology and health service research. British journal of haematology. 2010 Mar;148(5):739-53.

9. Kyle RA, Gertz MA, Witzig TE, Lust JA, Lacy MQ, Dispenzieri A, Fonseca R, Rajkumar SV, Offord JR, Larson DR, Plevak ME. Review of 1027 patients with newly diagnosed multiple myeloma. InMayo Clinic Proceedings 2003 Jan 1 (Vol. 78, No. 1, pp. 21-33).

10. Terpos E. Multiple Myeloma: Criteria for Diagnosis and Response to Therapy. InImaging in Clinical Oncology 2018 (pp. 651-658).

11. Wong MJ, Taylor T. Clinical features and diagnosis of multiple myeloma. Dalhousie Medical Journal. 2016 Nov 21;43(1).

12. Xiao R, Miller JA, Margetis K, Lubelski D, Lieberman $\mathrm{IH}$, Benzel EC, Mroz TE. Predicting the progression of vertebral fractures in patients with multiple myeloma. The Spine Journal. 2016 Apr 1;16(4):510-5.

13. Zhu Y, Yan F, He B, Shen J, Xiao Z. A Case Report of Non-Secretory myeloma with Renal Failure. Clin Oncol. 2016;1:1056.

14. Birgegård $G$, Gascón $P$, Ludwig $H$. Evaluation of anaemia in patients with multiple myeloma and lymphoma: findings of the European Cancer Anaemia Survey. European journal of haematology. 2006 Nov;77(5):378-86.

15. Ludwig $\mathrm{H}$, Pohl G, Osterborg A. Anemia in multiple myeloma. Clinical advances in hematology \& oncology: H\&O. 2004 Apr;2(4):233-41.

16. Kyle RA, Larson DR, Therneau TM, Dispenzieri A, Melton 3rd LJ, Benson JT, Kumar S, Rajkumar SV. Clinical course of light-chain smouldering multiple myeloma (idiopathic Bence Jones proteinuria): a retrospective cohort study. The Lancet Haematology. 2014 Oct $1 ; 1(1): 28-36$. 
17. Pacca RL, Silva JB, Carbinatto RB. Autoimmune hemolytic anemia and hyperglobulinemia leading to the diagnosis of multiple myeloma. Revista brasileira de hematologia e hemoterapia. 2017 Dec;39(4):357-9.

18. Bruns I, Cadeddu RP, Brueckmann I, Fröbel J, Geyh S, Büst S, Fischer JC, Roels F, Wilk CM, Schildberg FA, Hünerlitürkoglu AN. Multiple myelomarelated deregulation of bone marrowderived CD34+ hematopoietic stem and progenitor cells. Blood. 2012 Sep 27;120(13):2620-30.

19. Medhi K, Kalita D, Chopra A, Anand M, Raina V, Kumar R. Multiple myeloma presenting with coexisting severe marrow hypoplasia. Indian J Pathol Microbiol. 2008;51:543-45.
20. Corso A, Mangiacavalli S. Non-Secretory Myeloma: Ready for a new Definition?. Mediterranean journal of hematology and infectious diseases. 2017;9(1)

21. Katzmann JA, Dispenzieri A, Kyle RA, Snyder MR, Plevak MF, Larson DR, Abraham RS, Lust JA, Melton III LJ, Rajkumar SV. Elimination of the need for urine studies in the screening algorithm for monoclonal gammopathies by using serum immunofixation and free light chain assays. InMayo Clinic Proceedings 2006 Dec 1 (Vol. 81, No. 12, pp. 1575-1578). 